\title{
Concept designs for NASA's Solar Electric Propulsion Technology Demonstration Mission
}

\author{
Melissa L. McGuire ${ }^{1}$, Kurt J. Hack ${ }^{2}$, David H. Manzella ${ }^{3}$, and Daniel A. Herman ${ }^{4}$ \\ NASA Glenn Research Center, 21000 Brookpark Road, Cleveland, Ohio, 44135
}

\begin{abstract}
Multiple Solar Electric Propulsion Technology Demonstration Mission were developed to assess vehicle performance and estimated mission cost. Concepts ranged from a $10,000 \mathrm{~kg}$ spacecraft capable of delivering $4000 \mathrm{~kg}$ of payload to one of the Earth Moon Lagrange points in support of future human-crewed outposts to a $180 \mathrm{~kg}$ spacecraft capable of performing an asteroid rendezvous mission after launched to a geostationary transfer orbit as a secondary payload. Low-cost and maximum Delta-V capability variants of a spacecraft concept based on utilizing a secondary payload adapter as the primary bus structure were developed as were concepts designed to be co-manifested with another spacecraft on a single launch vehicle. Each of the Solar Electric Propulsion Technology Demonstration Mission concepts developed included an estimated spacecraft cost. These data suggest estimated spacecraft costs of $\$ 200 \mathrm{M}-\$ 300 \mathrm{M}$ if $30 \mathrm{~kW}$-class solar arrays and the corresponding electric propulsion system currently under development are used as the basis for sizing the mission concept regardless of launch vehicle costs. The most affordable mission concept developed based on subscale variants of the advanced solar arrays and electric propulsion technology currently under development by the NASA Space Technology Mission Directorate has an estimated cost of $\$ 50 \mathrm{M}$ and could provide a Delta- $\mathrm{V}$ capability comparable to much larger spacecraft concepts.
\end{abstract}

\section{Nomenclature}

$\begin{array}{ll}\text { ACS } & =\text { Attitude Control System } \\ A R R M & =\text { Asteroid Redirection Robotic Mission } \\ A T K & =\text { Alliant Techsystems Inc. } \\ A U & =\text { Astronomical Unit } \\ B O L & =\text { Beginning of Life } \\ D D U & =\text { Direct Drive Unit } \\ D S S & =\text { Deployable Space Systems } \\ E E L V & =\text { Evolved Expendable Launch Vehicle } \\ E M-L 2 & =\text { Earth Moon Lagrange point two } \\ E O L & =\text { End of Life } \\ E P & =\text { Electric Propulsion } \\ E P S & =\text { Electric Power System } \\ E S P A & =\text { EELV Secondary Payload Adaptor } \\ G E O & =\text { Geostationary Orbit } \\ G R C & =\text { Glenn Research Center } \\ G T O & =\text { Geostationary Transfer Orbit } \\ H E O M D & =\text { Human Exploration and Operations Mission Directorate } \\ H G A & =\text { High Gain Antenna } \\ I M L E O & =\text { Initial Mass in Low Earth Orbit } \\ I S P & =\text { In Space Propulsion (Program) }\end{array}$

\footnotetext{
${ }^{1}$ Aerospace Engineer, GRC Mission Architecture and Analysis Branch, NASA Glenn Research Center M.S. 105-3, AIAA Member.

2 Aerospace Engineer, GRC Mission Architecture and Analysis Branch, NASA Glenn Research Center M.S. 105-3, AIAA Senior Member.

${ }^{3}$ Chief Engineer Office, 21000 Brookpark Road/Mail Stop 86-8, AIAA Member.

${ }^{4}$ In-Space Propulsion Systems Branch, 21000 Brookpark Road/Mail Stop 86-8, AIAA Associate Fellow.
}

American Institute of Aeronautics and Astronautics 


$\begin{array}{ll}\text { Isp } & =\text { Specific Impulse } \\ \text { L2 } & =\text { semi-stable second Lagrange Point } \\ \text { LEO } & =\text { Low Earth Orbit } \\ \text { LGA } & =\text { Lunar Gravity Assist } \\ \text { LLO } & =\text { Low Lunar Orbit } \\ M E L & =\text { Master Equipment List } \\ M G A & =\text { Mass Growth Allowance } \\ M L I & =\text { Multi-Layer Insulation } \\ N E A & =\text { Near Earth Asteroid } \\ N E A R & =\text { Near Earth Asteroid Rendezvous } \\ N E X T & =\text { NASA Evolutionary Xenon Thruster } \\ P P U & =\text { Power Processing Unit } \\ R C S & =\text { Reaction Control System } \\ R O S A & =\text { Roll Out Solar Array } \\ S A D A & =\text { Solar Array Drive Assembly } \\ S A S & =\text { Solar Array System } \\ S E P & =\text { Solar Electric Propulsion } \\ S I P & =\text { Spiral In Phase } \\ S O P & =\text { Spiral Out Phase } \\ S M A & =\text { semi-major Axis } \\ S T M D & =\text { Space Technology Mission Directorate } \\ T D M & =\text { Technology Demonstration Mission } \\ X e & =\text { Xenon } \\ \mu S E P S A T & =\text { micro solar electric propulsion satellite } \\ \triangle V & =\text { Delta V (change in velocity) }\end{array}$

\section{Introduction}

$\mathrm{T}$ HE primary objectives of NASA's Solar Electric Propulsion (SEP) Technology Demonstration Mission (TDM) are to develop and demonstrate an enabling propulsion capability based on next generation solar electric propulsion technologies as part of an integrated system with extensibility to higher power systems. Multiple mission concepts were developed during the mission formulation phase of the SEP TDM to provide insight into technical benefit and estimated total life cycle cost of different approaches. A number of these mission concepts, many of which were developed by industry under contract to NASA Glenn Research Center, have previously been reported on. ${ }^{1}$ These initial mission concepts detailed how a high power SEP TDM was cost prohibitive relative to anticipated project resources. As a result an in-house mission concept development team was established to investigate alternate mission concepts that afford improved affordability either through enabling a cost-sharing partner or by minimizing launch vehicle costs by flying as a secondary payload or by launching with a second spacecraft as a co-manifested payload. The SEP TDM in-house concept design team has developed five different SEP demonstration missions and vehicle concept designs, listed in table 1 . These designs are summarized in this paper.

The in-house SEP TDM mission concept development team was tasked with incorporating SEP technologies concurrently under development by the NASA Space Technology Mission Directorate (STMD) into mission concepts that addressed the following top-level objectives:

1. Perform an in-space demonstration that advances the maturity of high-power electric propulsion technology and high-power solar array power system technology in relevant space environments and operational regimes

2. Demonstrate integrated SEP spacecraft operational modes associated with orbit transfer (Power systems, thermal control, attitude control, etc.)

3. Demonstrate extensible high-power electric propulsion and solar array power system technologies and integrated SEP spacecraft operational modes that can be adapted for use in next-generation, higher power SEP systems

4. Provide an SEP-based transportation capability that provides performance advancement over that previously demonstrated. 
Further detailed guidance was provided to constrain the mission concept designs: a spiral from Low Earth Orbit (LEO) to the final destination was required to assure operation in challenging environments and the mission was required to utilize the solar array system (SAS) technology being developed by STMD. It was also considered desirable to demonstrate simultaneous operation of multiple thrusters. Not all mission concepts complied with this guidance. The logistics support mission to the

Table 1: SEP Concept Design Listing

\begin{tabular}{|l|l|}
\hline Partner Focus & Concept Mission \\
\hline NASA HEOMD & EM-L2 Logistics support mission \\
\hline Multiple & Various secondary payload concepts \\
\hline NASA HEOMD/SMD & NEA Precursor mission \\
\hline Commercial & Ride Share, ESPA based structure \\
\hline Commercial & Ride Share, Maximum propellant loading \\
\hline ESPA Micro Spacecraft & HSEPSAT \\
\hline
\end{tabular}
Earth Moon Lagrange point (EM-L2), the Near Earth Asteroid (NEA) precursor mission and Ride Share mission concepts utilized $30 \mathrm{~kW}$ SAS arrays. Multiple simultaneous thruster operations were implemented in the EM-L2 logistics support concept designs, the NEA precursor mission and the Ride Share concept designs. The EM-L2 logistic support mission focused on the use of an SEP stage to supply cargo to an EM L2 staging location. The goal of the concept design study was to maximize the amount of payload that a $30 \mathrm{~kW}$ system could deliver to EM-L2 using an SEP spiral trajectory to support a potential human-tended outpost at that location. ${ }^{2}$ The secondary payload concept design used the structure of an Evolved Expendable Launch Vehicle (EELV) secondary payload adapter (ESPA) as the main structure of the vehicle. The NEA precursor mission concept design considered two concepts: one demonstrating a single 2000 second Hall effect thruster with the characteristics of the technology under development by STMD, and the second demonstrating dual thruster operation with two NASA Evolutionary Xenon Thruster (NEXT) gridded ion engines in order to contrast the mission impacts of the two thruster types. The two Ride Share mission concepts were chosen to investigate a different approach for reducing mission cost. These missions demonstrated (SAS) wing deployment and mission operations similar to the type of mission an SEP tug would encounter. Lastly, a small SEP spacecraft concept, constrained to fit within the $\sim 180 \mathrm{~kg}$ ESPA payload volume and mass constraints, provided a demonstration platform using subscale HEOMD high voltage thrusters to buy down future mission risk at low cost.

\section{SEP TDM Concept Missions}

The SEP Concept designs were all focused on flight demonstration mission concepts enabling high performance solar electric propulsion for a range of cross-cutting applications. Funded by the STMD, the concept designs primarily focused on $30 \mathrm{~kW}$-Class SEP vehicles capable of demonstrating the technology that future Human Exploration and Operations Mission Directorate (HEOMD), Space Technology Mission Directorate (STMD), Science Mission Directorate (SMD) and commercial missions would require.

These mission concepts presented below were executed to a sufficient level of detail to show feasibility. These concepts were not intended to provide an optimized flight design with sufficient detail for execution of the missions. As a result, the detailed trade studies necessary to create an optimized design have been identified, but not executed as part of the SEP concept development team activity.

\section{A. L2 Logistics Support Mission Concept}

In 2012 EM-L2 was internally identified within NASA as a potential near-term human-crewed exploration destination for planning purposes. A human-tended waypoint at EM-L2 could serve as a gateway for the capability-driven exploration of cis-lunar space, asteroids, the Moon, Mars and its moons. The EM-L2 logistics concept focused on a $30 \mathrm{~kW}$-class SEP vehicle capable of supporting Low Earth Orbit (LEO) to EM-L2 waypoint cargo delivery needs. ${ }^{3}$ The goals of the SEP mission concept were to complete the LEO to EM-L2 transfer in less than two years and deliver a 5000 $\mathrm{kg}$ payload mass to EM-L2. The total mission duration at the EM-L2 point was assumed to be one year, after which time the SEP Concept Spacecraft vacated the halo orbit and entered a disposal orbit.

The EM-L2 logistic support mission concept was based

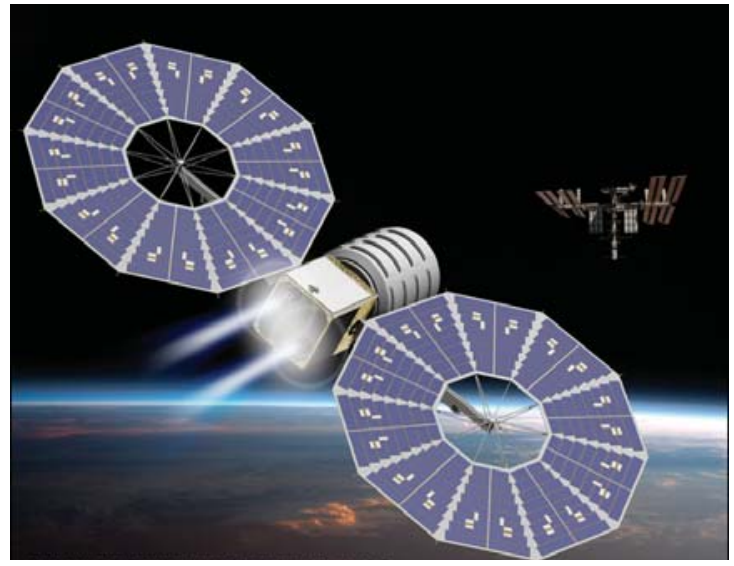

Figure 1. L2 Logistics Support Mission. Spacecraft capable of delivering $5000 \mathrm{~kg}$ payload to EM-L2. 
on a Falcon 9 launched to a $400 \mathrm{~km}$. circular LEO at 28.5 degrees inclination. The Falcon 9 was chosen as the lowest cost launch vehicle option with an assumed injected mass in Low Earth Orbit (IMLEO) capability of 9,953 $\mathrm{kg}$ to $400 \mathrm{~km}$. LEO at 28.5 degrees inclination. After being launched to LEO, the SEP spacecraft completes an orbit transfer from LEO to EM-L2. One there, the SEP Stage enters a 5,000 km. radius halo orbit about the EM-L2 point; maintain this orbit for one year before entering a disposal orbit.

For this concept, two ATK MegaFlex solar array wings were sized to provide $40 \mathrm{~kW}$ BOL, with an array mass fraction of $106 \mathrm{~W} / \mathrm{kg}$ at BOL at 1-AU, $60 \mathrm{deg} \mathrm{C}$ at with a desired input voltage of $160 \mathrm{~V}$ to the Solar Array Drive Assembly (SADA) at EOL. The solar arrays were chosen to be scalable for higher power missions. The two MegaFlex Wings utilized $8 \times 8 \mathrm{~cm}, 29 \%$ ZTJ solar cells with $61 \mathrm{~cm}^{2}$ of active area to reduce cell related stringing costs. For increased radiation protection during the Earth spiral leg of the trajectory, a 5.5 mil germanium substrate thickness was incorporated including in the array mass sizing.

The primary EP system was based on two XR-12 thrusters ${ }^{4}$ operating with a $160 \mathrm{~V}$ input to the PPUs using Moog two-axis thruster gimbals for control authority. Operating at $12 \mathrm{~kW}$, these higher power thrusters help to minimize the trip time from LEO to the EM-L2 destination. This concept assumed that the EP system under development by STMD had similar concepts as XR-12 system, as this one of the options being considered for that development at the time of this concept development. Six General Dynamics (formerly Lincoln Composites) $0.5 \mathrm{~m}$ diameter tanks capable of storing roughly $500 \mathrm{~kg}$ per tank, held the Xe propellant for the mission. A simple cylinder represented the payload, similar in size to the Cygnus pressurized cargo vehicle that mounted above the SEP concept spacecraft in the Falcon 9 fairing for the launch configuration.

The total dry mass of the SEP Stage with an allocation of $21 \%$ MGA on dry mass was $2384 \mathrm{~kg}$. To perform the mission, $2910 \mathrm{~kg}$ of Xe and $50 \mathrm{~kg}$ of Hydrazine were carried for EP and RCS propellant needs respectively. A payload mass of $4000 \mathrm{~kg}$ resulted in a total wet mass in IMLEO of the SEP vehicle with payload of $9344 \mathrm{~kg}$. Assuming an LV adaptor and separation system mass of $236 \mathrm{~kg}$, and a Falcon 9 performance of $9953 \mathrm{~kg}$, the total lift mass of the SEP Vehicle (SEP plus adaptor) of $9580 \mathrm{~kg}$ allows for a $372 \mathrm{~kg}$ dry mass margin in the launch vehicle performance. This SEP option provides an alternative way to affordably support human missions at EM-L2, a destination unreachable using an all-chemical solution with a Falcon 9 Launcher. The total estimated mission cost of this concept, including launch and mission operations, was estimated at $\$ 542$ million. The SEP spacecraft estimated cost was less than $\$ 300$ million.

\section{B. Secondary Payload Concepts}

Taking advantage of the cost-reduction inherent in flying as a secondary payload, the second concept examined as an application of SEP TDM technology demonstration was the secondary payload option. ${ }^{5}$ For this concept, initially several low cost launch options were considered (ESPA-based, GEO comsat secondary payload, and accommodation in SpaceX Dragon Trunk) before narrowing down to one: the ESPA based concept. For this concept, to be more affordable, the smaller $180 \mathrm{~kg}$-capable, 4m-fairing ESPA was used as the primary structure for this mission concept. Two $8.3 \mathrm{~m}$ diameter MegaFlex arrays and a single Xe tank with $220 \mathrm{~kg}$ capacity were accommodated within the ESPA bus structure. With $220 \mathrm{~kg}$ of propellant, and an Isp of $2000 \mathrm{sec}$ for the Hall thruster, this spacecraft is capable of producing a

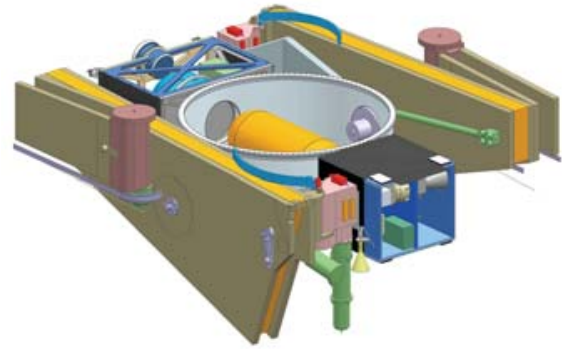

Figure 2. Secondary Payload SEP concept. total $\Delta \mathrm{V}$ of $4500 \mathrm{~m} / \mathrm{s}$. With some reconfiguration, a second tank could also be accommodated. With a second tank the total Xe propellant capacity increased to $450 \mathrm{~kg}$ and the spacecraft would be capable of producing $8300 \mathrm{~m} / \mathrm{s} \Delta \mathrm{V}$. The total wet mass, using the single tank with $220 \mathrm{~kg} \mathrm{Xe}$, with $43 \%$ growth on dry mass, of this concept was 1066 $\mathrm{kg}$. This mass fits within the assumed mass allocation of $1200 \mathrm{~kg}$ for a secondary payload. These performance capabilities for this mission concept enable: $\sim 20 \mathrm{x}$ the acceleration of the Dawn spacecraft, $\sim 4.5 \mathrm{~km} / \mathrm{s} \Delta \mathrm{V}$ in 30 days and $\sim 8.2 \mathrm{~km} / \mathrm{s} \Delta \mathrm{V}$ in 60 days.

This concept illustrated the possibility to physically large, high-power solar array at power levels up $30 \mathrm{~kW}$ within the volume constraints of a small secondary payload. Using a bottoms up cost estimation technique, the total spacecraft cost was estimated to be $\$ 200 \mathrm{M}$. A 30-kW, ESPA-sized SEP vehicle concept with direct-drive offers the potential for very significant performance within a small package with relatively low cost.

\section{NEA Precursor Mission Concept}

SEP TMD concepts based on missions to a Near Earth Asteroid (NEA) were similarly developed. The mission objective was to explore asteroids that are candidates for future human space missions beyond Earth as previously 
proposed $^{6}$ while also satisfying the objectives of the SEP TDM. The high efficiency of SEP and the high $\Delta \mathrm{V}$ required for this application make this approach well suited for this type of solar system exploration. ${ }^{7}$ However, in order to satisfy the SEP TDM objectives a LEO spiral out trajectory was incorporated. The incorporation of the spiral out had the added benefit of enabling the use of a much smaller class launch vehicle with an assumed IMLEO capability of only $1800 \mathrm{~kg}$. Because this was a technology demonstration mission, all subsystems were designed assuming zero fault tolerance.

After initial trajectory analysis survey of asteroid targets, and an initial spacecraft dry mass assessment, the decision was made to complete two spacecraft concepts in the $15 \mathrm{~kW}$ total power to the EP system class. Both concepts used SEP to spiral to a Lunar Gravity Assist (LGA) from a LEO initial orbit of $400 \mathrm{~km}$ circular LEO at $28.5^{\circ}$. After LGA and escape

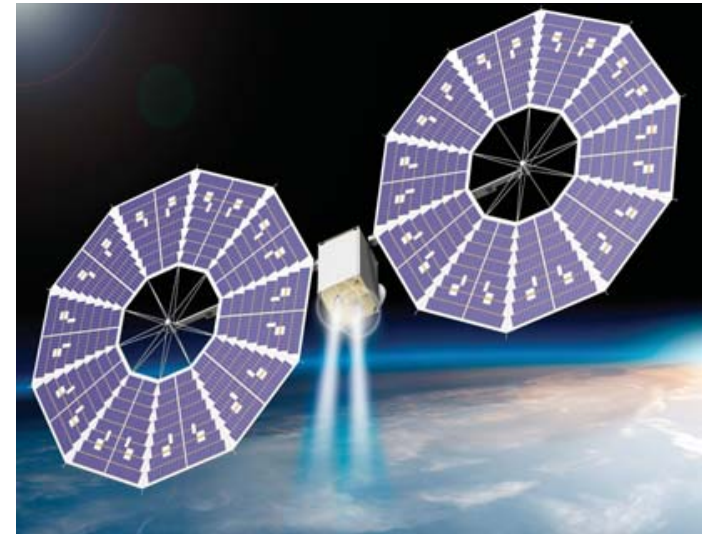

Figure 3. NEA Precursor. Dual NEXT thruster NEA precursor spacecraft concept. into heliocentric space SEP was used to arrive at the NEA.

For the trajectory analysis asteroid 2000_SG344 was used. The first concept included a Hall-based electric propulsion system using direct drive and the Deployable Space Systems (DSS) Roll Out Solar Array (ROSA) under development by STMD. Higher specific impulse ion thrusters were included in the second concept as was MegaFlex solar arrays. The two concepts used different SAS in order to show application of the two arrays currently under technology development. Both concepts used a communications system based on the NEAR X-band system using a 1.4m high gain antenna (HGA) and an Attitude Control System/Reaction Control System (ACS/RCS) system with MR-103G thrusters and reaction wheels based on the Dawn spacecraft. The Hydrazine for RCS was stored in a single $0.36 \mathrm{~m}$ diameter cylindrical tank. The two spacecraft concepts differed primarily in thruster system and SAS.

The first concept, designated Concept 1 (C1), focused on the application of Hall Thrusters to the NEA precursor

Table 2: Concept $\mathrm{C} 1$ single $15 \mathrm{~kW}$ Hall Thruster with ROSA array

\begin{tabular}{|l|c|}
\hline \multicolumn{2}{|l|}{$\begin{array}{l}\text { Concept C1: Single 15 kW Hall with ROSA } \\
\text { Array }\end{array}$} \\
\hline SEP stage MEL & $\begin{array}{c}\text { Basic Mass } \\
\text { (kg) }\end{array}$ \\
\hline Structures & 147.3 \\
\hline Power & 221.4 \\
\hline ACE/RCS & 49.3 \\
\hline Main Propulsion & 104.3 \\
\hline $\begin{array}{l}\text { Total propellant (Main + } \\
\text { RCS) }\end{array}$ & 857.2 \\
\hline Thermal Control & 122 \\
\hline Communications & 21.9 \\
\hline Avionics & 159.5 \\
\hline $\begin{array}{l}\text { SEP Stage Basic Wet } \\
\text { Mass }\end{array}$ & $\mathbf{1 6 6 8 . 8}$ \\
\hline $\begin{array}{l}\text { SEP Stage Basic Dry } \\
\text { Mass }\end{array}$ & $\mathbf{8 1 1 . 6}$ \\
\hline System Growth (20\% dry) & 162.3 \\
\hline $\begin{array}{l}\text { SEP Stage total dry mass } \\
\text { with growth }\end{array}$ & 973.6 \\
\hline LV adaptor & 80 \\
\hline Science Payload & 20 \\
\hline $\begin{array}{l}\text { Total wet mass with } \\
\text { growth in LEO }\end{array}$ & 1931 \\
\hline LV performance to LEO & 1800 \\
\hline
\end{tabular}
mission. The Hall thruster system assumed $15 \mathrm{~kW}$ of input power to a single thruster operating at a total efficiency of $60 \%$ and an Isp of 2200 sec. The total estimated trip time was approximately 700 days, with 150 days spent spiraling from LEO to LGA. The total Xe propellant load was approximately $800 \mathrm{~kg}$. The main power system was composed of two $3 \mathrm{~m}$ by $13.6 \mathrm{~m}$ DSS ROSA wings providing $18 \mathrm{~kW} \mathrm{BOL}$ and $16 \mathrm{~kW}$ EOL with a single DDU (Direct Drive Unit) operating at $300 \mathrm{~V}$ for the single Hall thruster. The thermal system consisted of cold plates mounted to the top of the spacecraft, radiators mounted on three of the four sides. Heat pipes, louvers, MLI, heaters, thermostats and temperatures sensors and were sized to dissipate a maximum heat load of approximately $1200 \mathrm{~kW}$. The thermal system was sized primarily by the power requirements and operations during the LEO to escape spiral. The primary structure was based on $4 \mathrm{Al}-\mathrm{Li}$ longerons with composite honeycomb panels built around a two Dawn heritage Xe tanks capable of storing $450 \mathrm{~kg}$ Xe each at 1750 psi. The Hall thruster/DDU configuration has lower trip time, cost and mass than NEXT/PPU concept discussed subsequently, but the lower specific impulse of the Hall system required more propellant to perform the mission resulting in a full-margined wet mass greater than the $1800 \mathrm{~kg}$ IMLEO goal. Further refinement of the spacecraft concept would be necessary to either lengthen the mission to save propellant, reduce mass in the subsystems in order to fit within the assumed launch mass, or investigate launching to lower initial altitude. Table 2 shows the Master Equipment List (MEL) of concept C1. For mass growth, $20 \%$ was applied to the basic dry mass in order to calculate the total mass with growth. A launch vehicle adaptor of $80 \mathrm{~kg}$ was added to calculate the total mass in LEO in order to measure whether the total mass fit within the assumed launch vehicle performance of $1800 \mathrm{~kg}$ to $400 \mathrm{~km}$ circular LEO. Using the MEL, the total estimated mission cost for concept $\mathrm{C} 1$ with launch vehicle and mission operations was $\$ 398 \mathrm{M}$. The spacecraft point cost was estimated to be roughly $\$ 220 \mathrm{M}$ not including the completion of the technology development for the arrays or thrusters.

American Institute of Aeronautics and Astronautics 
The second concept, known as Concept 2 (C2), evaluated using NEXT ion thrusters. This concept demonstrated two thruster operation using two NEXT thrusters at a total power of $14 \mathrm{~kW}$ (each NEXT thruster running at $7 \mathrm{~kW}$ ) to the EP system at a thruster efficiency of $70 \%$ and an Isp of $4190 \mathrm{sec}$. The total trip time from launch to asteroid arrival was 550 days, with 360 days spent spiraling from LEO to Earth escape. The total Xe propellant load was approximately $500 \mathrm{~kg}$. For this concept two $9 \mathrm{~m}$ diameter ATK Mega Flex array wings were used. This SAS was sized to provide $20 \mathrm{~kW}$ BOL and $17 \mathrm{~kW}$ EOL operating with a $160 \mathrm{~V}$ output for the EP system and a $28 \mathrm{~V}$ output to the battery for the other subsystems. The main propulsion system consisted of two operational NEXT thrusters, without a spare, each with a $160 \mathrm{~V}$ PPU in what is known as a $2+0$ configuration. The primary structure was based on 4 Al-Li longerons with composite honeycomb panels built around a single Cassini heritage Xe tank capable of holding $525 \mathrm{~kg}$ Xe capacity at 3700 psi. The thermal system consisted of radiators, heat pipes, cold plates and louvers sized to dissipate $1700 \mathrm{~W}$ thermal. The thermal system was sized primarily by the power requirements and operations during the LEO to escape spiral. Table 3 shows the MEL of concept C2. A MGA of $20 \%$ was applied to the basic dry mass in order to calculate the total mass with growth. The NEXT thruster/PPU higher Isp reduces main propellant mission requirement at the cost of trip time. This allowed for Concept 2 to fit within the $1800 \mathrm{~kg}$ IMLEO goal. Using the MEL, the estimate mission cost for concept $\mathrm{C} 1$ with launch vehicle and mission operations was $\$ 410 \mathrm{M}$. The spacecraft cost was estimated to be roughly $\$ 230 \mathrm{M}$. This costing did not include technology development for the arrays or thrusters.

Both of the NEA precursors SEP Concepts demonstrate feasibility of a lower cost SEP for NEA precursor mission as an SEP TDM option. This NEA mission provides an opportunity to demonstrate and quantify the effects on power and propulsion systems during the lengthy LEO spiral trip times experienced by high power SEP missions. Of particular interest to the application of solar arrays for future large payloads, is the effect of the long dwell time in LEO and exposure to Earth's albedo and Van Allen belts on thermal, electronic and power systems. With a launch mass target limit of $1800 \mathrm{~kg}$, both initial concepts were slightly over the mass goal. Concept C1 is over the $1800 \mathrm{~kg}$ LV capacity by $131 \mathrm{~kg}$ and Concept C2 is over by only $4 \mathrm{~kg}$. With a goal of spacecraft cost around $\$ 200 \mathrm{M}$, both concepts were within $10 \%$ of the final spacecraft cost goal. The primary difference between the two concept masses

Table 4 Comparison of Hall, NEXT concepts with Dawn Spacecraft reference

\begin{tabular}{|c|c|c|c|}
\hline & C1 Hall & C2NEXT & Dawn \\
\hline Subsystem & \begin{tabular}{|c|}
$\begin{array}{c}\text { Basic Mass } \\
(\mathrm{kg})\end{array}$ \\
\end{tabular} & $\begin{array}{c}\text { Basic Mass } \\
(\mathrm{kg})\end{array}$ & Mass $(\mathrm{kg})$ \\
\hline Bus Primary and Secondary Structures & 147 & 140 & 133 \\
\hline Power & 221 & 310 & 207 \\
\hline ACS/RCS & 49 & 54 & 96 \\
\hline Main Propulsion & 104 & 158 & 136 \\
\hline Main Propellant & 843 & 490 & 425 \\
\hline Thermal Control & 122 & 157 & 44 \\
\hline Communications & 22 & 22 & 26 \\
\hline Avionics & 160 & 175 & 105 \\
\hline M/MOD Protection & 0 & 0 & 0 \\
\hline SEP Stage Basic Wet Mass & 1669 & 1505 & 1171 \\
\hline Total Propellant (Main + RCS) & 857 & 508 & 471 \\
\hline SEP Stage Basic Dry Mass & 812 & 996 & 701 \\
\hline System Growth (20\% dry) & 162 & 199 & \\
\hline SEP Stage Total Dry Mass with Growth & 974 & 1195 & \\
\hline Launch Configuration & C1 Hall & C2 NEXT & Dawn \\
\hline SEP Stage Total Dry Mass with Growth & 974 & 1195 & 701 \\
\hline Main Propellant (Xe) & 843 & 490 & 425 \\
\hline RCS Propellant (Hydrazine) & 14 & 18 & 46 \\
\hline P/L Interface & 0 & 0 & unknown \\
\hline LV Adapter & 80 & 80 & unknown \\
\hline LV Separation System & 0 & 0 & unknown \\
\hline Payload & 20 & 20 & 47 \\
\hline Total Mass in Low Earth Orbit & 1931 & 1804 & 1171 \\
\hline Launch Vehicle performance to LEO & 1800 & 1800 & unknown \\
\hline \begin{tabular}{|l} 
Margin \\
\end{tabular} & -131 & -4 & unknown \\
\hline
\end{tabular}
is in the main propulsion hardware mass and cost. Specifically, the Hall thruster concept used a DDU and the NEXT Thruster concept used a PPU. The DDU system saves mass over the PPU system, at the cost of thruster operation limitation and additional dollars. The primary driver in the propellant difference is the operating mission Isp. The Lower Isp Hall system in concept $\mathrm{C} 1$ requires more $\mathrm{Xe}$ to perform the mission than the higher Isp NEXT system. The difference in the thermal control system mass is driven by the higher thermal waste heat of the PPU vs. the DDU.

Since both concepts $\mathrm{C} 1$ and $\mathrm{C} 2$ were NEA missions, the Dawn spacecraft mission ${ }^{8}$ was used as a reference against which to measure the feasibility of the two designs. Table 4 shows how the masses of concepts $\mathrm{C} 1$ and $\mathrm{C} 2$ compared with the final masses and performance numbers of the Dawn spacecraft. Dawn was launched direct to Earth escape $(\mathrm{C} 3=5$ $\mathrm{km}^{2} / \mathrm{s}^{2}$ ) on a Delta II on September 27, 2007 and targeted the asteroids Vesta and Ceres. Dawn was envisioned as a mission to explore main belt asteroids in order to provide insights into the formation and evolution of the solar system. Dawn's main propulsion system consists of three Xenon ion thrusters, based 
on the heritage NSTAR system ${ }^{9}$ from Deep Space 1, each operating at $3100 \mathrm{sec}$. The main power system consists of two solar arrays with BOL power of $10.3 \mathrm{~kW}$ at $1 \mathrm{AU}$ and $1.3 \mathrm{~kW}$ at $3 \mathrm{AU}$. Concepts $\mathrm{C} 1$ and $\mathrm{C} 2$ also targeted a NEA similar to those visited by Dawn, but instead of being launched direct to Earth escape, as the Dawn spacecraft was, each spent time spiraling from LEO to Earth escape. This Earth spiral took advantage of the higher efficiency of the low thrust EP system to deliver more mass to Earth escape on a smaller launch vehicle than would have been possible if the spacecraft was launched direct to escape. While it increases the delivered mass to heliocentric space, this spiral from LEO to escape adds the time that the spacecraft spends going through the Earth's radiation belts. As a result, both radiation shielding of electronic components, thermal system hardware and solar array shielding of the Concepts $\mathrm{C} 1$ and $\mathrm{C} 2$ are higher than that used on the Dawn spacecraft design. Another area of difference between the concepts is Xe propellant mass. Operating at $2000 \mathrm{sec}$, the Hall concept C1 requires the most propellant of the concepts $\mathrm{C} 1$ and $\mathrm{C} 2$, to perform the NEA mission. Both Concepts $\mathrm{C} 1$ and $\mathrm{C} 2$ required more Xe propellant than Dawn, but perform additional Earth spiral departure maneuvers that the Dawn spacecraft did not have to perform. Both concepts bottoms up subsystem mass estimated compare favorably to the Dawn actual masses. Additional masses in Xe, Thermal system, and Avionics radiation shielding are attributed to the long Earth spiral inherent in this demonstration mission. While cost was a figure of merit in these concept designs, both concepts were within $10 \%$ of $\$ 200 \mathrm{M}$ total cost for spacecraft, which was higher than the desired $\$ 200 \mathrm{M}$ with launch costs, but do compare with Dawn actuals.

Future work would focus on mass reductions through packaging and mission design. The following subsystems and areas could benefit from the additional refinement: Avionics - refine harness masses, revisit particle shielding vs. metal thickness, refine the power requirements in power modes, trade mass vs. levels of integration; assessment of DCIU options (stand alone box, incorporation in PPU, or incorporation in avionics), Thermal design - revisit temperature environment requirements for electronics, revisit configuration of electronics on cold plates, Solar Array System (SAS) - improve sizing based on updated vehicle power requirements, improve harness estimate, revisit voltage of MegaFlex from $120 \mathrm{~V}$ to $160 \mathrm{~V}$ and impacts to EPS, Electrical Power System (EPS) - Analysis of radiation tolerance vs. shielding, validate battery sizing and power requirement for mission timelines, trade packaging options for weight reduction, thermal, power.

\section{Ride Share Mission Concept}

Having looked at secondary payloads as an SEP TDM option, a follow-on effort investigated the concept of an SEP Spacecraft as a comanifested or Ride Share launch vehicle payload. A Ride Share is not a secondary payload, and does not have to defer to requirements from a primary payload. Rather, a ride share simply shares the cost and payload capability of a launch vehicle with the possibility of reduce overall mission cost by sharing launch vehicle costs. The goals of the ride share mission concepts were to explore the impacts of a rideshare configuration on an SEP

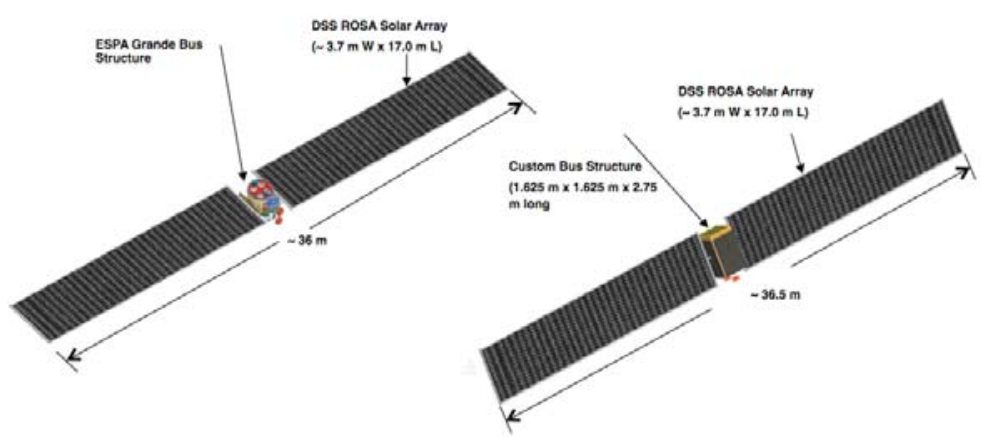

Figure 4. Ride Share Concept Designs. Shown on Left is the ESPA Grande based ride share SEP Stage. Shown on Right is traditional bus ride share SEP Stage.

spacecraft design and to provide a reduced cost concept with the maximum capability possible. In order to accommodate the likely initial orbit of the other co-manifested spacecraft, the Rideshare concept was assumed to be launched to GTO, and then would follow a low thrust spiral trajectory from GTO to GEO, performing inclination change along the way, and then spiral back down from GEO to a circular LEO to demonstrate operation in all environments of interest. The integrated system technology demonstration aspect of this concept included the control of the dynamic interactions of solar array, thruster, and communications systems simultaneous pointing into and out of shadow and during out-of-plane steering. By utilizing a trajectory with time spent spiraling through the Van Allen belts SEP operation would be demonstrated consistent in order to demonstrate the operations required for HEOMD SEP missions. As with the spiral from LEO to escape in the secondary payload concepts, the requirements on this concept were related to those necessary for multiple potential future high power SEP applications under consideration by HEOMD. These include performing a lengthy spiral through the Earth's magnetic field, including plane changes while operating at least two thrusters simultaneously. The science payload requirements were left 
undefined but a $50 \mathrm{~kg}$ allocation was retained in the spacecraft concept design. Because the SEP TDM concept designs were all required to be low cost technology demonstrators, all subsystems were designed to be single string.

As with the secondary payload concepts, the Ride Share concept study looked at two versions of the SEP spacecraft to perform the mission. The first concept used an ESPA Grande as the basis for the structure of the spacecraft. An ESPA Grande is a larger EELV payload adapter than the standard ESPA. The second concept used a more traditional cylindrical bus as the basis for the structure. Both the SEP spacecraft rideshare concepts assumed a shared launch of a Falcon 9 with another payload, with the SEP spacecraft supporting the other spacecraft on top. The final mass allocation of the concept was half a Falcon 9 performance to GTO, assumed to be $5755 \mathrm{~kg}$. Assuming half of the Falcon performance is available, the spacecraft mass was limited to $2878 \mathrm{~kg}$. After subtracting $10 \%$ for launch vehicle performance margin, and $51 \mathrm{~kg}$ for the portion of the launch vehicle adaptor that stays with the Falcon 9 left $2538 \mathrm{~kg}$ as the estimated mass limit for the SEP Ride Share concepts.

Both concepts performed the same trajectory maneuvers. In order to run a spiral trajectory that would spend a similar amount of time as a high power, large mass LEO to escape HEOMD spiral mission would spend going through the Van Allen Belts, ${ }^{10}$, the Ride share concepts performed the trajectory in two phases. The power level of the EP system determined the amount of time spent spiraling through the radiation belts. Because the use of a $30 \mathrm{~kW}$ solar array would result in trip times through the Van Allen Belts of much less than the year the high power HEOMD missions would experience, the trajectory was run using only $15 \mathrm{~kW}$ to the EP system. The full $30 \mathrm{~kW}$ solar array structure was included on the vehicle, but the arrays were only populated with enough solar cells to produce $15 \mathrm{~kW}$ for the EP system and additional power for housekeeping and growth to cover the power margin. The $15 \mathrm{~kW}$ to the Hall thruster system was used by one Hall thruster for some of the mission modes or split between two Hall thrusters running at half power in other mission modes.

The first phase, Spiral Out Phase (SOP) started from the launch from Falcon 9 to GTO (185 km x 35,786 km at $26.5^{\circ}$ inclination) through the orbit raising and circularization to GEO and reduction of the orbit inclination to $0^{\circ}$. This phase demonstrated full power operation of the thruster for half the time and two thruster operation (although at half power) for the other half, as well as plane change maneuvers and radiation exposure demonstration. This phase itself was divided into two phases:

- SOP Phase I: GTO to Highly elliptical orbit > 15,000 km (1 thruster at full power - $15 \mathrm{~kW}$ total power to thruster)

- SOP Phase II: Highly elliptical orbit $>15,000 \mathrm{~km}$ to GEO (2 thrusters at $1 / 2$ power to demo dual thruster operation - $15 \mathrm{~kW}$ total power to EP system)

The second major phase was the Spiral In Phase (SIP). This phase started from GEO (35,786 km altitude; $0^{\circ}$ inc) through to LEO $\left(\sim 1000 \mathrm{~km}, 0^{\circ}\right.$ in) below proton belts. This phase itself was divided into two phases:

- SIP Phase I: GEO to an elliptical orbit with the semi-major axis $<15,000 \mathrm{~km}$ (1 thruster at full power $15 \mathrm{~kW}$ total power to EP system)

- SIP Phase II: an elliptical orbit with the semi-major axis < 15,000 km to LEO ( 1 thruster at $1 / 3$ power to delay transit through belts $-5 \mathrm{~kW}$ total power to EP system)

This would satisfy the technology demonstration goal of demonstrating SAS deployment and the operation/characterization of performance in environments similar to the high power HEOMD mission. The power system for both the ESPA based and traditional bus Ride Share spacecraft concept consisted of two ROSA array wings with a single DDU each. The wings were sized to provide the minimum power requirements of the EP system and housekeeping during the spiral from GTO to GEO. Each wing provides $8.6 \mathrm{~kW}$ power (high and low voltage), using the $15 \mathrm{~kW}$ structural wing size. The two wing SAS was sized to be capable of supplying $15 \mathrm{~kW}$ maximum power to the EP system. The electrical power system provided high voltage power distribution (300V) and a $\mathrm{Li}$ ion battery for use during eclipse operations. A commercially derived SADA was assumed for the arrays.

The propulsion system technology demonstrated two thruster operations and thruster operation at the maximum power of $15 \mathrm{~kW}$. Both the ESPA and traditional Ride Share mission concepts used Hall Thrusters for Main EP and blow down hydrazine for RCS. The main EP system consisted of two $15 \mathrm{~kW}$ Hall thrusters, each with a 300V DDU operating in a $2+0$ configuration (Two active thrusters and no spares) and a Moog Xenon thruster gimbal for articulation. The blow-down Hydrazine System consisted of two thruster pods with 3 thrusters per pod (total 6 thrusters) using $2 \times 0.26 \mathrm{~m}$ diameter cylindrical RCS tanks to store the hydrazine.

Since the major difference between the ESPA and traditional Ride share is the primary structure, most of the spacecraft bus subsystems are the same across the two concepts. The communications system used was an S-band with four OMNI antennas because this was not a deep-space mission. The ACS System used Sun sensors (4), and Reaction Wheels (3). The thermal system was comprised of radiators mounted on 3 of the four sides, heat pipes, louvers, MLI, cold plates, louvers. The thermal system was sized to dissipate a thermal load of $700 \mathrm{~W}$. 


\section{ESPA Based Ride Share Mission Concept}

'The goals of the ESPA based ride share mission concept were to explore the impacts of a rideshare configuration on an SEP spacecraft concept design and to provide a low cost bus concept, using the ESPA Grande ring itself as the spacecraft main structure. The ESPA Grade has the same $1.6 \mathrm{~m}$ diameter as the standard ESPA ring, but can be up to $1.4 \mathrm{~m}$ in height. This additional height provides more volume for the spacecraft components. Assuming an SEP vehicle initial launch mass of $1 / 2$ Falcon 9 performance to GTO, the ESPA based structure can carry the other $1 / 2$ Falcon 9 payload on top $(2800 \mathrm{~kg})$. The ESPA Grande ring baseline concept for structure was capable of accommodating 4 commercial composite-overwrapped tanks carrying $900 \mathrm{~kg}$ ( $820 \mathrm{~kg}$ usable) of Xe. The total basic mass, without growth, of the ESPA concept was $1173 \mathrm{~kg}$. The total wet mass of the concept with a baselined 30\% MGA was $2446 \mathrm{~kg}$. The SEP total wet mass with growth of 2446 results in a remaining 93 $\mathrm{kg}$ of additional mass on top of the MGA, system growth, and LV performance margin. Based on the MEL as summarized in Table 5 a spacecraft cost of $\$ 234 \mathrm{M}$ was estimated. Launch costs and technology development were not part of this estimate.

\section{Traditional Cylindrical Bus Ride Share Mission Concept}

The goals of the second ride share mission concept were to explore the impacts of a rideshare configuration on an SEP spacecraft design for a low-cost concept, using a traditional

Table 5. ESPA Based Ride Share MEL

\begin{tabular}{|l|c|}
\hline ESPA Based Ride Share Concept \\
\hline SEP stage MEL & $\begin{array}{c}\text { Basic Mass } \\
(\mathbf{k g})\end{array}$ \\
\hline Payload & 38.5 \\
\hline ACS & 23.3 \\
\hline C\&DH & 53.7 \\
\hline Communications & 6.5 \\
\hline Electrical Power System & 80.9 \\
\hline Solar Array System & 160.0 \\
\hline Thermal Control & 115.4 \\
\hline RCS Hardware & 7.8 \\
\hline RCS propellant & 19 \\
\hline EP hardware & 173.4 \\
\hline Xenon & 902 \\
\hline $\begin{array}{l}\text { Structures and } \\
\text { Mechanisms }\end{array}$ & 513.4 \\
\hline Total Basic Dry Mass & 1173 \\
\hline Total Growth (30\% dry) & 352 \\
\hline $\begin{array}{l}\text { SEP Stage total dry mass } \\
\text { with growth }\end{array}$ & $\mathbf{1 5 2 5}$ \\
\hline LV adaptor & 51 \\
\hline Total wet mass in GTO & 2446 \\
\hline LV performance to GTO & 2590 \\
\hline LV Margin & 93 \\
\hline
\end{tabular}
spacecraft main bus structure design. This concept was able to

accommodate five commercial composite-overwrapped tanks capable

Table 6 Traditional Cylindrical Bus Ride Share Concept MEL

\begin{tabular}{|c|c|}
\hline \multicolumn{2}{|c|}{$\begin{array}{l}\text { Traditional Cylindrical Bus Ride Share } \\
\text { Concept }\end{array}$} \\
\hline SEP stage MEL & $\begin{array}{c}\text { Basic Mass } \\
(\mathrm{kg})\end{array}$ \\
\hline Payload & 38.5 \\
\hline ACS & 23.3 \\
\hline $\mathrm{C} \& \mathrm{DH}$ & 53.7 \\
\hline Communications & 6.5 \\
\hline Electrical Power System & 80.9 \\
\hline Solar Array System & 160.0 \\
\hline Thermal Control & 115.4 \\
\hline RCS Hardware & 7.8 \\
\hline RCS propellant & 19 \\
\hline EP hardware & 193.8 \\
\hline Xenon & 1129 \\
\hline $\begin{array}{l}\text { Structures and } \\
\text { Mechanisms }\end{array}$ & 349.9 \\
\hline Total Basic Dry Mass & 1030 \\
\hline Total Growth (30\% dry) & 309 \\
\hline $\begin{array}{l}\text { SEP Stage total dry mass } \\
\text { with growth }\end{array}$ & 1339 \\
\hline LV adaptor & 51 \\
\hline Total wet mass in GTO & 2487 \\
\hline LV performance to GTO & 2590 \\
\hline LV Margin & 36 \\
\hline
\end{tabular}
of carrying $1130 \mathrm{~kg}$ (1027 kg usable) of Xe. The total basic mass of the traditional design is $1030 \mathrm{~kg}$. Applying the required 30\% growth on dry mass, the total wet mass with MGA was $2487 \mathrm{~kg}$. The SEP total wet mass with growth of $2487 \mathrm{~kg}$ results in an additional mass margin of $36 \mathrm{~kg}$ top of the MGA, system growth, and LV performance margin. Based on the MEL as summarized in Table 6 a spacecraft cost of $\$ 239 \mathrm{M}$ was estimated. Launch costs and technology development were not part of this estimate.

All differences between the two Ride Share designs result from the difference in primary structure. The total structure based on use of an ESPA Grande is inherently heavier than the cylindrical bus structure. The primary structure mass on the two designs is within $30 \mathrm{~kg}$ of each other, with the ESPA grande primary structure being the slightly heavier of the two. However, the cylindrical bus structure does not need the secondary items needed to attach items to the ESPA concept. The ESPA Grande structure total mass is $163 \mathrm{~kg}$ greater than that of the cylindrical bus structure. The lighter structure mass in the cylindrical design allowed for incorporation of a fifth tank (the ESPA grande carries four tanks) to carry additional Xe. With a total Xe capacity of $902 \mathrm{~kg}$, and a useable propellant of $820 \mathrm{~kg}$, the total $\Delta \mathrm{V}$ of the $2000 \mathrm{~s}$ Hall thruster system on the ESPA-Grande based design was $7769 \mathrm{~m} / \mathrm{s}$. For the cylindrical bus design, with a total Xe capacity of $1128 \mathrm{~kg}$, and a useable propellant of $1026 \mathrm{~kg}$, the total $\Delta \mathrm{V}$ of the 2000 s Hall thruster system was $9895 \mathrm{~m} / \mathrm{s}$. While the ESPA design used the heritage of the ESPA Grande for its central bus structure, this required additional secondary structures and ultimately resulted in a design that was able to carry less $\mathrm{Xe}$ and perform less $\Delta \mathrm{V}$ than the traditional cylindrical bus concept. The cost of both concepts was within less than $5 \%$ without taking into account technology development and launch costs. 


\section{E. ESPA Payload Class $\mu$ SEPSAT Mission Concept}

Having examined the trade space of 30kW SEP TDM missions, the final SEP concept developed a micro solar electric propulsion satellite ( $\mu$ SEPSAT). Focusing on the sub $1 \mathrm{~kW}$ class of thrusters, the primary goal of this $\mu$ SEPSAT concept design was to provide as much $\Delta \mathrm{V}$ capability as possible (i.e. maximize the available propellant) within the mass and volume constraints of an ESPA payload capability $(180 \mathrm{~kg})$ at a minimal cost using near term technology. ${ }^{11}$ This free flying ESPA-class payload would provide a subscale demonstration of an STP TDM thruster and buy down risk for the higher power HEOMD applications by demonstrating an appropriate Earth spiral trajectory. The focus of the design was to provide the maximum $\Delta \mathrm{V}$ capablity in this size of free flying spacecraft.

Prior to the design, a mission analysis survey was conducted to find where a $180 \mathrm{~kg}$ SEP stage could fly based on mass fractions and previous designs performed by NASA Glenn Reseach Center's COMPASS conceptual design team, the strawman concept started with an assumed $70 \mathrm{~g} \mathrm{Xe}$ propellant capablity. The trajectory analysis investigated multiple mission options including several NEA targets as well as Low Lunar Orbit (LLO) as stressing cases consistent with a

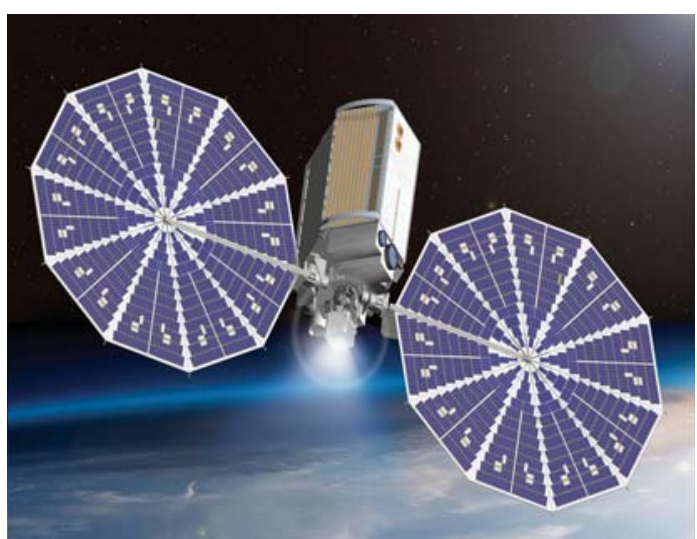

Figure 5. $\mu$ SEPSAT concept design. Small SEP spacecraft designed as an sub $1 \mathrm{~kW}$ class ESPA payload. Xe allocation of $70 \mathrm{~kg}$. Similar to the analysis for the NEA precurser concept, the trajectory analysis assumed a launch to GTO (Geostationary Transfer Orbit) and a spiral from GTO to LGA (Lunar Gravity Assist) in order to gain energy from the moon for Earth escape. Trajectory analysis for the LLO orbit capture modeled lunar capture through a weak stability boundary insertion. Based on these analyses, the concept design focused on an asteroid rendezvous mission with the asteroid Itokawa as the stressing case for all the subsystems in the design. The Itokawa mission required the most propellant of the targets examined and with maximum solar distances of 1.7 AU would serve as the most challenging environment requirements for most of the subsystems. For these trajectories, $400 \mathrm{~W}$ to the EP system was sufficient to rendezvous with Itokawa. Raising the

Table 7: $\mu$ SEPSAT Spacecraft MEL

\begin{tabular}{|c|c|}
\hline \multicolumn{2}{|l|}{$\mu$ SEPSAT Concept design } \\
\hline SEP stage MEL & $\begin{array}{c}\text { Basic Mass } \\
(\mathrm{kg})\end{array}$ \\
\hline Payload & 4.4 \\
\hline ACS & 5 \\
\hline $\mathrm{C} \& D H$ & 3.8 \\
\hline Communications & 6.5 \\
\hline Electrical Power System & 8.8 \\
\hline Solar Array System & 8.2 \\
\hline Thermal Control & 12.3 \\
\hline RCS Hardware & 1.6 \\
\hline EP hardware & 13.2 \\
\hline Xenon & 72 \\
\hline $\begin{array}{l}\text { Structures and } \\
\text { Mechanisms }\end{array}$ & 23.8 \\
\hline Total Basic Dry Mass & 87 \\
\hline Total Growth (30\% dry) & 10 \\
\hline $\begin{array}{l}\mu \text { SEPSAT total dry mass } \\
\text { with growth }\end{array}$ & 108 \\
\hline $\begin{array}{l}\mu \text { SEPSAT total wet mass } \\
\text { with growth }\end{array}$ & 185 \\
\hline $\begin{array}{l}\text { LV performance to GTO } \\
\text { (after adaptor) }\end{array}$ & $178(2)$ \\
\hline LV Margin & $(-7)$ \\
\hline
\end{tabular}

EP system power to $600 \mathrm{~W}$ reduced mission time and the propellant requirement slightly, but not enough to justify the additional mass and volume necessary to accomondate the larger solar arrays needed to provide an additional $200 \mathrm{~W}$ of power. The final trajectory option used as the Design Reference Mission (DRM) for this concept assumed a $400 \mathrm{~W}$ EP system operating at an Isp of $1420 \mathrm{~s}$, launched to GTO to spiral to a C3 of $-2 \mathrm{~km} 2 / \mathrm{s} 2$ to perform an LGA to reach Earth escape. Once at escape, the EP system continued with a low thrust heliocentric spiral to the asteroid Itokawa, inserting coast phases in to the trajectory where needed.

The power system consisted of two UltraFlex arrays based on those used by the NASA Phoenix ${ }^{12}$ mission scaled down to $1.4 \mathrm{~m}$. In order to provide power at two different voltages, one for housekeeping and one for the EP system, the arrays were divided in to a $407 \mathrm{~W} / 28 \mathrm{~V}$ segment and a 459W/300 V segment respectively (BOL, $1 \mathrm{AU}, 28 \mathrm{C}$ ). Operating at solar distances as far as 1.7AU on the outbound leg of the trajectory, the two UltraFlex solar arrays provide $>800 \mathrm{~W}$ of power for the EP and houskeeping systems.

The Main Propulsion System consisted of a single thruster EP system and RCS thrusters sharing a single Xe tank. The single Hall thruster was operated at a maximum input power of $400 \mathrm{~W}$ with an Isp of $1420 \mathrm{sec}$ using a single dedicated DDU $(300 \mathrm{~V})$. The xenon propellant was stored in a single commercial composite-overwrapped tanks sized to carry $72 \mathrm{~kg}$ of xenon. The propellant is used for both the Hall thrusters and the cold gas RCS thrusters operating at an Isp of 25s. This configuration yielded a total $\Delta \mathrm{V}$ capability of $\sim 5600 \mathrm{~m} / \mathrm{s}$.

The key technical features of this concept include: a maximum xenon load of $72 \mathrm{~kg}$ stored in a flight-qualified, composite-overwrapped propellant tank; a previously-demonstrated $400 \mathrm{~W}$ Hall thruster capable of providing 1420

10

American Institute of Aeronautics and Astronautics 
seconds of specific impulse with $43 \%$ efficiency; and a pair of $1.5 \mathrm{~m}$ diameter UltraFlex solar arrays based on the $2.2 \mathrm{~m}$ wings successfully flown on Mars Phoenix. The $180 \mathrm{~kg} \mu$ SEPSAT concept has sufficient propulsion capability to enable interplanetary missions to be performed from a geostationary Transfer Orbit (GTO) overcoming the current limitations of secondary-payload-sized spacecraft. Using the MEL summarized in Table 7 for cost estimating resulted in a spacecraft cost not including payload of $\$ 50 \mathrm{M}$. Since secondary payloads in the $180 \mathrm{~kg}$ class typically do not have primary propulsion systems capable of performing much $\Delta \mathrm{V}$, the $\mu$ SEPSAT concept can be cost enabling for missions with small, low mass payloads, that would otherwise not be possible because of their high $\Delta \mathrm{V}$ requirements.

\section{Conclusions Forward Work}

Multiple SEP TDM mission concepts were developed by NASA to investigate various options for performing a SEP TDM. These concepts ranged from an approximately $10,000 \mathrm{~kg}$ concept capable of delivering $4000 \mathrm{~kg}$ of payload to EM-L2 in support of future human-crewed outposts launched on a medium-class launch vehicle to a 180 $\mathrm{kg}$ concept capable of performing an asteroid rendezvous mission after launched to GTO as a secondary payload. Low-cost and maximum $\Delta \mathrm{V}$ capability variants of a spacecraft concept based on utilizing a secondary payload adapter as the primary bus structure were developed as were concepts designed to be co-manifested with another spacecraft on a single launch vehicle. Each of SEP TDM concepts developed included an estimated spacecraft cost. The data suggest estimated spacecraft costs of $\$ 200 \mathrm{M}-\$ 300 \mathrm{M}$ if $30 \mathrm{~kW}$-class solar arrays and the corresponding electric propulsion system currently under development by STMD are used as the basis for sizing the mission concept regardless of launch vehicle cost, even for those concepts that could be launched as secondary payloads. The most affordable mission concept developed based on subscale variants of the advanced solar arrays and EP had a $\Delta \mathrm{V}$ capability comparable to the much larger SEP TDM concepts with at an estimated cost of $\$ 50 \mathrm{M}$.

\section{Acknowledgments}

This research was carried out at NASA Glenn Research Center. The authors wish to thank the members of the in-house SEP concept design team: Jeff Woytach, Laura Burke, Tyler Hickman, James Fincannon, Robert Jones, Thomas Kraft, Terrance Condrich, David Nawrocki, Edie Parrott, Waldy Sjauw, Dr. David Smith, Dzu K. Le, Glenn Williams, Fred Wolff, John Siamides, Carl Blaser, and Thomas Parkey. Without the experience and expertise of this team, these designs would not have been possible. Thank you to the COMPASS design team of NASA Glenn led by Steve Oleson for providing much in the way of instruction on how to run small teams of experts in concurrent engineering designs. The authors wish to extend their sincere thanks to the TDM program managers, Dr. Meg Nazario and Timothy Smith. Lastly, the authors wish to thank their management, especially Derrick Cheston, Maria Babula, Dave Jacobson and Gary Kelm, for their unwavering support and motivation to continue this challenging work and finishing its documentation.

\section{References}

\footnotetext{
${ }^{1}$ Smith, B., Nazario, M, and Manzella, D, “Advancement of a 30kW Solar Electric Propulsion System Capability for NASA Human and Robotic Exploration Missions," IAC-12-C4.4.2, 63rd International Astronautical Congress, Naples, Italy, October 2012.

2 "Proposed Orbits and Trajectories for Human Missions to the Earth-Moon L2 Region" Joshua B. Hopkins, William Pratt, Caley Buxton, Selena Hall, Andrew Scott, Robert Farquhar, David Dunham, Proceedings of the 64th International Astronautical Congress, Beijing, China, September 2013

${ }^{3}$ Woytach, Jeff, "SEP Capability Demonstration Mission, In-House Concept Development Engineering Review Board", May 29, 2012, 20120529 ERB Presentation rev G.pptx.

${ }^{4}$ Welander, Benjamin, Jeff Monheiser, Nicole Meckel, Kristi de Grys and Peter Peterson, Vadim Khayms, "Demonstration of the XR-12 Hall Current Thruster," EPC-2013-451, Presented at the 33rd International Electric Propulsion Conference, The George Washington University, Washington, D.C., USA October 6 - 10, 2013.

${ }_{6}^{5}$ Brophy, John and Tim Larson, "SEP TDM-HT (High-Tech), August 7, 2012, SEP TDM-HT Status 201200807.pptx.

6 A. F. Cheng, A. S. Rivkin, K. Hibbard, et. al, "NEAR-EARTH ASTEROID SURVEY PRECURSOR TO HUMAN EXPLORATION." 42nd Lunar and Planetary Science Conference (2011)

${ }^{7}$ Brophy, John R., Muriel Noca, "Electric Propulsion for Solar System Exploration," JOURNAL OF PROPULSION AND POWER, Vol. 14, No. 5, September -October 1998
} 


\footnotetext{
${ }^{8}$ Thomas, Valerie C., et. al, "The Dawn Spacecraft", Space Sci Rev (2011) 163:175-249, DOI 10.1007/s11214-011-9852-2, Received: 23 August 2011 / Accepted: 28 October 2011 / Published online: 3 December 2011.

9 Anderson, John R., Keith D. Goodfellow, et. al, "Performance Characteristics of thNe STAR Ion Thruster During an OnGoing Long Duration Ground”, 0-7803-5846-5/00/\$10.00, 2000 IEEE.

10 Brophy, J., et al., "300-kW Solar Electric Propulsion System Configuration for Human Exploration of Near-Earth Asteroids," AIAA-2011-5514, 47 ${ }^{\text {th }}$ AIAA Joint Propulsion Conference, San Diego, CA, August, 2011.

${ }^{11}$ McGuire, Melissa L., "SEP TDM Internal Concept Team microSEPSat Concept Designs (Option 3b), Final design briefing charts", June 10, 2014, SEP_TDM_microSEPSat_FinalCharts_June102004_v1.ppt

${ }^{12}$ Coyne, Jeffrey W., and William E. Jackson, and Chris Lewicki, "Phoenix Electrical Power Subsystem - Power at the Martian Pole", 7th International Energy Conversion Engineering Conference, 2 - 5 August 2009, Denver, Colorado, AIAA 20094518.
} 